\title{
Study of serum sodium levels in neonates receiving phototherapy for unconjugated hyperbilirubinemia
}

\author{
Usharani. M \\ Assistant Professor, Dept. of Physiology, Govt. Theni Medical College, Theni, Tamil Nadu, India \\ *Corresponding Author: \\ Email: usharani3520@gmail.com
}

\begin{abstract}
Introduction: In the neonatal period one of the frequently faced problems is jaundice. The American Academy of Paediatrics has published a set of practice parameters for the treatment of unconjugated hyperbilirubinemia in healthy term infants. We follow the guidelines published by the American Academy of Paediatrics. In current practice if the bilirubin reaches a level that would require phototherapy and if it is predicted to raise we will start phototherapy. A major role is being played by phototherapy in the treatment of hyperbilirubinemia. This management method may result in inherent complications. In this study level of serum sodium study is estimated in full term neonates those who are receiving phototherapy for jaundice.

Aim and Objective: To determine the level serum sodium and to compare the levels before and after phototherapy in full-term hyperbilirubinemic neonates.

Methods: We started the study after obtaining approval from Ethical Committee. From the neonate's mother informed consent and written consent has been attained after explaining about the study. The medical history of the neonate is obtained from the neonate's mother. General examination and systemic examination of the neonate are carried out. A prospective study has been performed on 30 full-term jaundiced neonates. Neonates included in the study are 15 males and 15 females who have been receiving phototherapy for jaundice. We excluded neonates having risk factors from this study. Laboratory tests which are performed includes estimation of total serum bilirubin by Diazo method and estimation of serum sodium level by Ion selective electrode analyser method. These tests are being carried out prior to the commencement and following forty eight hours of initialising phototherapy. Blood samples taken from the newborn babies before the commencement of phototherapy in which serum levels of sodium and bilirubin are assessed is regarded as control group. Blood samples taken from the neonates 48 hours following establishment of phototherapy in which serum levels of sodium and bilirubin are determined is regarded as study group.

Results: Paired t test has been used for making analysis of statistics of the levels of sodium and bilirubin in serum. Forty eight hours following the commencement of phototherapy, there is a considerable reduction in levels of serum bilirubin which is being significant. No significant change is found in serum sodium levels. Serum sodium before phototherapy has been $141.44 \pm 1.75 \mathrm{mEq} / \mathrm{L}$ and forty eight hours after initialising phototherapy it has been $140.54 \pm 1.59 \mathrm{mEq} / \mathrm{L}$.

Conclusion: Though our study shows no significant alteration in levels of serum sodium in term infants exposed to phototherapy appropriate monitoring of electrolytes subsequent to phototherapy is suggested. Accordingly we can avoid dyselectrolytemia and its related complications.
\end{abstract}

Keywords: American Academy of Paediatrics, Phototherapy, Serum bilirubin, Serum sodium, Term neonates, Unconjugated hyperbilirubinemia.

Received: $14^{\text {th }}$ October, 2017

\section{Introduction}

A commonly faced difficulty, neonatal hyperbilirubinemia by definition is rise in levels of total serum bilirubin more than $5 \mathrm{mg}$ in one $\mathrm{dL}$ or $86 \mu \mathrm{mol}$ in one litre.

In the first week of living slightly additional than $50 \%$ of all neonates become apparently jaundiced. Neonatal jaundice may be recognized in about $60 \%$ of infants born at full-term during first week subsequent to being born. Hyperbilirubinemia in neonate's being a manifestation of undeveloped conduit of excretion of bilirubin by the liver. All neonates have some hyperbilirubinemia and most have benign outcomes when monitored and treated, if necessary, in a timely manner.

Severe unconjugated hyperbilirubinemia giving rise to deposition of unconjugated bilirubin in basal ganglia and brain stem nuclei and producing brain damage is kernicterus. A practical consideration which deals through the treatment in the healthy newborn born at term's hyperbilirubinemia was formed during 1994 October by the Subcommittee on Hyperbilirubinemia and Provisional Committee for Quality Improvement of the American Academy of Pediatrics (AAP). 
In three means neonatal hyperbilirubinemia can be managed:

(a) Phototherapy: Convertion of bilirubin into substances which can bypass the liver's system of conjugation and excreted through the urine is the mechanism of involved in phototherapy; (b) By exchange transfusion; (c) Hastening the usual metabolic pathways for clearance of bilirubin through the action of pharmacologic substances.

Phototherapy must be given to newborn having total serum bilirubin in excess of 12 $\mathrm{mg} / \mathrm{dL}$. Lowering the levels of bilirubin by increasing its elimination is the objective of phototherapy and it is effectively done by phototherapy. When the total serum bilirubin reduces less than the level at which phototherapy was started phototherapy can be safely terminated in infants who were treated.

Phototherapy has a major function in the prevention as well as in managing hyperbilirubinemia. Side effects of phototherapy are insensible water loss, watery diarrhea, hypocalcemia, bronze baby syndrome, hyperthermia, tanning of the skin, intolerance to feed, retinal damage, genotoxicity, erythemia and increased blood flow to the skin. One of the side effects is diarrhea. Very small number of studies are currently in existence that depicts the side effects of phototherapy on the levels of sodium in serum. Since diarrhea causes change in electrolyte levels in this study we determine the levels of serum sodium and compare these levels before and after phototherapy in full term neonates with unconjugated hyperbilirubinemia.

\section{Aim}

1. To determine the level of sodium and bilirubin in serum.

2. To compare the levels before and after phototherapy in full term hyperbilirubinemic neonates.

\section{Material and Methodology}

Prospective study has been conducted in the Department of Paediatrics, Government Theni Medical College Hospital, in association along with the Physiology Department, Government Theni Medical College, Theni. The study is initiated after obtaining the approval of the ethical committee. It has been carried out after explaining the procedures in detail and getting written informed consent from the subject's mother. This study is performed on 30 full-term jaundiced neonates (15 males and 15 females) receiving phototherapy.
A detailed history including maternal history , antenatal history, mode of delivery, immediate postnatal history, history of phototherapy in sibling, death of sibling due to hypocalcemia, family history of seizure disorders and congenital anomalies (as given by the subject's mother) is recorded.

Head to foot examination was done. Icterus, skin changes, anaemia, congenital anomalies are noted and documented.

Control group: comprises of samples of blood of the neonates in which level of bilirubin in serum and sodium are measured earlier than the commencement of phototherapy.

Study group: comprises of samples of blood taken from the neonates in which level of serum bilirubin and sodium are measured subsequent to forty eight hrs of phototherapy.

Inclusion criteria: Term neonates with indirect hyperbilirubinemia which includes

1. Cephalohematoma

2. Physiological jaundice

3. Idiopathic

4. Breast milk jaundice

5. Breast feeding jaundice

6. External bruising

7. Large for gestational age

Exclusion criteria:

1. Neonatal asphyxia.

2. Preterm infants.

3. Infants of diabetic mothers.

4. Infants undergoing exchange transfusion.

5. Hemolytic anaemia / $\mathrm{Rh} / \mathrm{ABO}$ incompatability

6. Conjugated hyperbilirubinemia.

7. Sepsis.

8. Congenital malformations.

9. Respiratory distress

Blood investigations: The investigations done in this study are measurement of indirect bilirubin in serum using Diazo method and measurement of serum sodium using Ion selective electrode analyser method.

\section{Results and Observation}

The levels of serum bilirubin and serum sodium variation in term neonates who have been receiving phototherapy for jaundice are analysed before and after phototherapy using Paired " $t$ " test. A p value of 0.05 is considered as significant.

Statistical analysis of serum bilirubin and sodium level in serum done in our study are given in table form.

We evaluate the level of total bilirubin in serum before as well as after phototherapy in this table. It has been identified that mean $\pm \mathrm{SD}$ of 
that of total bilirubin in serum prior to phototherapy as $14.04 \pm 0.71 \mathrm{mg}$ per dl. Mean \pm $\mathrm{SD}$ of that of total bilirubin in serum subsequent to phototherapy is $8.13 \pm 0.40 \mathrm{mg}$ per $\mathrm{dl}$. The level of total bilirubin in serum has declined significantly following phototherapy having 0.001 as a $p$ value.

The mean \pm SD of serum sodium before phototherapy has been $141.44 \pm 1.75 \mathrm{mEq}$ per litre and after phototherapy it is $140.54 \pm 1.59$ $\mathrm{mEq}$ per litre. There has been no significant alteration in the levels of sodium in serum previous to phototherapy and also after phototherapy.

We have compared the levels of serum bilirubin and serum sodium prior to and following phototherapy in the bar diagrams.

\section{Discussion}

1. This study has been carried out on 30 term neonates with jaundice managed with phototherapy. The levels of bilirubin in serum and also sodium are estimated and compared prior to phototherapy and subsequent to phototherapy. After 48 hours of phototherapy no significant decrease in the levels of sodium in serum has been detected in our study.

2. Normal values of serum sodium ranges from 135 to $145 \mathrm{mEq} / \mathrm{L}$. Hyponatremia occurs when the level of sodium in serum falls below $135 \mathrm{mEq} / \mathrm{L}$. It is an exceedingly frequent electrolyte abnormality. Both total sodium in the body and total water present in the body decide the concentration of sodium in the serum.

3. Hyponatremia occurs when the proportion of water to that of sodium is enhanced. This situation can arise with elevated, little or normal ranges of body sodium. Analogous condition happens wnen body water is raised, decreased or normal.

4. Sodium is an important nutrient that adjusts $\mathrm{pH}$, blood volume, osmotic equilibrium and blood pressure.

5. Sodium plays a major role in preserving charge balances in cell membranes, usually in operation outside the cell walls. Since sodium ion is positively charged it contradicts with potassium ion. Potassium ion is present within cell walls. It is responsible for creating a gradient called as the membrane potential.

6. The equilibrium of sodium has influence in the creation of membrane potential, permitting the body to direct charge-driven activities such as transmission of nerve impulse and normal muscle action. The quantity of sodium present in the body besides decides the amount of extracellular fluid distribution, making it crucial for preserving blood pressure.

\section{Conclusion}

Curtis et al (1989) made studies about diarrhoea occurring in neonates with jaundice those who were treated using phototherapy. Severe decrease in sodium uptake of was revealed in the study done in neonates who obtained phototherapy for jaundice.

Dee Beresford and Glenys Conolly in the textbook named Neonatal Intensive Care Nursing suggests that babies receiving phototherapy can contain imbalances in sodium which were caused by inadequate replacements of fluids.

Apart from the works of Curtis MD et al (1981) the differential consequences of other electrolytes due to phototherapy still has not been explored by the other workers. There are very small number of studies dealing with electrolyte changes induced by phototherapy.

We suggest estimation of levels of serum sodium in addition to the regular measurement of bilirubin in the serum for the neonates receiving phototherapy to avoid the development of dyselectrolytemia and its related complications.

\section{References}

1. American Academy of Pediatrics. Practice Parameter management of hyperbilirubinemia in healthy term and preterm newborn. Pediatric, 1994;94:554-6.

2. Avery GB, Pathophysiology and management of the newborn Lippincott Williams and Wilkins, fivth edition 1999;722-3.

3. Cremer RJ, Perrymann PW, Richards DH. Influence of light on the hyperbilirubinemia of infants. Lancet 1958;1(7030):1094-7.

4. Singh M. Care of the Newborn. 7th ed. New Delhi: Sagar Publications; 2010. Chapter 18, Neonatal Jaundice, p.254-74.

5. Maisels MJ. Jaundice in Neonatology, Pathophysiology and Management of Newborn, 4th edition, Avery G.B. p.765-820.

6. Cloharty JP, Stork AR, Eichenwald EC, Hansen AR. Manual of neonatal care. 7th ed, Philadelphia: Lippincott Willams and Wilkins; 2012. Chapter 26, Neonatal Hyperbilirubinemia, p.304 -39.

7. SourabhDutta. Phototherapy for neonatal jaundice, recent advances and controversies. Journal of Neonatalogy. 2001;1(1):39-44.

8. Curtis MD, Guandalini S, Fasano A, Ciccimarra F. Diarrhoea in jaundiced neonates treated with phototherapy: role of intestinal secretion. Arch Dis Child. 1989;64:1161-4. 
9. Dee Beresford and Glenys conolly. Fluid and electrolyte balance. Neonatal Intensive Nursing Care. $2^{\text {nd }}$ ed, p. 258 . 